\title{
Free electron laser-Fourier transform ion cyclotron resonance mass spectrometry facility for obtaining infrared multiphoton dissociation spectra of gaseous ions
}

\author{
Jose J. Valle and John R. Eyler \\ Department of Chemistry, University of Florida, P.O. Box 117200, Gainesville, Florida 32611-7200 \\ Jos Oomens, David T. Moore, and A. F. G. van der Meer \\ FOM-Institute for Plasma Physics Rijnhuizen, Edisonbaan 14, NL-3439 MN Nieuwegein, The Netherlands
}

Gert von Helden and Gerard Meijer

FOM-Institute for Plasma Physics Rijnhuizen, Edisonbaan 14, NL-3439 MN Nieuwegein, The Netherlands and Fritz-Haber-Institut der Max-Planck-Gesellschaft, Faradayweg 4-6, D-14195 Berlin, Germany

Christopher L. Hendrickson and Alan G. Marshall

National High Magnetic Field Laboratory, 1800 East Paul Dirac Drive, Tallahassee, Florida 32310-4005 and Department of Chemistry and Biochemistry, Florida State University, Tallahassee, Florida 32306

Gregory T. Blakney

National High Magnetic Field Laboratory, 1800 East Paul Dirac Drive, Tallahassee, Florida 32310-4005

(Received 14 July 2004; accepted 5 November 2004; published online 5 January 2005)

\begin{abstract}
A Fourier transform ion cyclotron resonance (FT-ICR) mass spectrometer has been installed at a free electron laser (FEL) facility to obtain infrared absorption spectra of gas phase ions by infrared multiple photon dissociation (IRMPD). The FEL provides continuously tunable infrared radiation over a broad range of the infrared spectrum, and the FT-ICR mass spectrometer, utilizing a 4.7 Tesla superconducting magnet, permits facile formation, isolation, trapping, and high-mass resolution detection of a wide range of ion classes. A description of the instrumentation and experimental parameters for these experiments is presented along with preliminary IRMPD spectra of the singly-charged chromium-bound dimer of diethyl ether $\left(\mathrm{Cr}\left(\mathrm{C}_{4} \mathrm{H}_{10} \mathrm{O}\right)_{2}^{+}\right)$and the fluorene molecular ion $\left(\mathrm{C}_{13} \mathrm{H}_{10}^{+}\right)$. Also presented is a brief comparison of the fluorene cation spectrum obtained by the FT-ICR-FEL with an earlier spectrum recorded using a quadrupole ion trap (QIT). (C) 2005 American Institute of Physics. [DOI: 10.1063/1.1841953]
\end{abstract}

\section{INTRODUCTION}

The low densities typically obtained in production of gas-phase molecular ions make the measurement of their infrared spectra challenging. Such spectra are useful in a wide variety of scientific fields ranging from astrophysics, where the spectral characterization of ionic polyaromatics is required to verify their hypothesized occurrence in the interstellar medium, ${ }^{1}$ to biochemistry, where the structure of protonated species is of key interest, ${ }^{2}$ to fundamental chemistry problems such as the study of reaction intermediates, ${ }^{3}$ differentiation of isomeric ions in mass spectrometry, and the study of metal cation binding to organic molecules, ${ }^{4}$ which is key to understanding many catalytic and biochemical reactions.

Small molecular ions can often be generated with relatively high densities in discharge and electron impact sources so that they can be studied directly by laser absorption spectroscopy, with sensitive detection methods employing, for instance, lock-in techniques. Direct absorption has been applied to ions in cells, ${ }^{5-7}$ fast ion beams, ${ }^{8,9}$ and supersonic expansions. ${ }^{10-12}$ Large molecular ions usually suffer from severe fragmentation in these sources so that other ionization sources and/or mass selectivity are required. However, ion densities may thereby be reduced such that direct laser absorption techniques become quite difficult, if not impossible, to apply.

One solution is to isolate the ions in a cryogenic inert matrix and subsequently record the infrared spectrum with, e.g., a Fourier transform infrared (FTIR) spectrometer. The ions can be generated in situ in the matrix by ultraviolet (UV) photoionization of the corresponding neutrals, ${ }^{13-15}$ or by mass-selective deposition of the ions into the matrix. ${ }^{16,17}$ Although matrix isolation spectroscopy has provided a vast amount of infrared data on ionic (and otherwise unstable) systems, drawbacks include the inability to distinguish absorption features of the ionic species from those of their neutral precursors and incomplete knowledge of the effect of the matrix on the infrared spectrum. ${ }^{18}$

The application of sophisticated "action spectroscopy" schemes, as opposed to direct absorption experiments, has greatly expanded the field of gas phase infrared spectroscopy of mass-selected ions over the past decade. ${ }^{19}$ Most of these methods combine laser-based infrared dissociation spectroscopy with mass spectrometric detection. Early studies include the work on hydrogen and hydronium cluster ions by Lee and co-workers. ${ }^{20-22}$ Since then, attaching a weaklybound "messenger" atom (or small molecule) to the ion of 
interest and detecting photodissociation of the complex as an indication of infrared absorption has become popular because relatively low-power laser sources will suffice for such experiments. In particular, noble gas atoms have been used as messengers since they are often detached following single photon absorption and, moreover, their weak interaction with the chromophore typically results in a spectrum which is virtually identical to that of the bare ion. ${ }^{23-26}$ However, the weak binding energy of these van der Waals complexes usually restricts their study to low temperature techniques, such as molecular beam sources or cooled ion traps. More strongly bound ions, such as coordination complexes and molecular ions, typically require absorption of multiple photons before the dissociation threshold can be reached. ${ }^{27-31}$ Nonetheless, mass-resolved photofragmentation spectroscopy can still be applied to such systems by the mechanism of infrared multiphoton dissociation (IRMPD) if sufficiently intense laser sources are available.

IRMPD is a noncoherent multiple photon absorption process that relies on rapid redistribution of the absorbed photon energy into a dense ensemble of background (ro-) vibrational states. ${ }^{32-34}$ This relaxation mechanism, commonly referred to as intramolecular vibrational redistribution (IVR), is facilitated by coupling of molecular eigenstates in combination with high vibrational state densities. ${ }^{35}$ Thus, the absorbing "bright" state is de-excited so that it can reabsorb an infrared photon. In the frequency domain, the rapid deexcitation, i.e., short lifetime of the bright state leads to a broadening of the absorption band. Once the typical linewidth becomes of the order of the average spacing of vibrational background levels, the molecule finds itself in the "quasi-continuum." Further photon absorption is enhanced as it becomes less wavelength dependent. Thus, the molecule can acquire high internal energy, eventually leading to dissociation. Note that molecules at high internal energies generally exhibit anharmonicity in their vibrational potentials, leading to (red-) shifts and broadening of infrared absorption bands. Therefore, although some caution is required in the analysis of IRMPD spectra, these spectral signatures may also be used to obtain an estimate of the anharmonic parameters. ${ }^{36}$

Since the 1970s, there has been considerable interest in IRMPD spectroscopy to induce isotopically selective dissociation, ${ }^{34,37,38}$ which could enable isotope enrichment. In order to overcome the typical dissociation thresholds of several $\mathrm{eV}$, the absorption of many (tens to hundreds of) infrared photons is necessary, requiring a powerful laser source, such as a gas discharge laser. The $\mathrm{CO}_{2}$ laser has mainly been used for this purpose, having as a main drawback its limited and discrete wavelength tunability. Two-laser methods, in which a tunable low-power laser is used to excite into the quasicontinuum and subsequently a high-power $\mathrm{CO}_{2}$ laser is used to induce photodissociation, have been applied to overcome this limitation. ${ }^{22,39-41}$ However, with the advent of infrared free electron lasers (FELs), it is now possible to apply IRMPD as a true wideband spectroscopic method. ${ }^{42}$

Unbound electrons form an ideal lasing medium, allowing FELs to be tuned continuously over a wide wavelength range. ${ }^{43,44}$ Their spectral properties are often combined with high pulse energy. Particularly in the infrared, for which large segments of the spectral range are not accessible to conventional lasers, the FEL is a unique source. However, because of their high cost and special instrumentation infrared FELs around the world are typically operated as national/ international user facilities. ${ }^{45}$ Historically, research with these lasers has mainly focused on condensed matter and optical physics, but more recently various applications in the field of gas-phase molecular physics and spectroscopy have developed. ${ }^{44}$ The FEL for Infrared eXperiments (FELIX) at the FOM-Institute for Plasma Physics Rijnhuizen ${ }^{46}$ has a high micropulse repetition rate (up to $1 \mathrm{GHz}$ ) and a macropulse length on the order of a few $\mu \mathrm{s}$, which corresponds roughly to the residence time of a room-temperature gasphase molecule in a typical $\mathrm{mm}$-sized laser focus. This particular feature renders FELIX very suitable for gas-phase studies of neutral molecules.

IRMPD spectroscopy of molecular ions has been implemented mostly with tandem mass spectrometers and ion traps. ${ }^{47}$ These devices allow for mass-selective isolation of the parent ion and subsequent mass resolved detection of product ions generated by IRMPD. In the 1980s and early 1990s, IRMPD of stored ions by use of line tunable $\mathrm{CO}_{2}$ lasers was reported mainly by Beauchamp and coworkers $^{48-50}$ and by Eyler and co-workers. ${ }^{51,52}$ In 2000, the first FEL-based ion IRMPD study, ${ }^{53}$ employing a simple radiofrequency quadrupole ion trap, ${ }^{54}$ was reported. Various ionic polycyclic aromatic hydrocarbon (PAH) systems have been investigated with that apparatus, ${ }^{36,53,55,56}$ motivated by their likely occurrence in the interstellar medium.

Based on these successful applications of an FEL to IRMPD spectroscopy of molecular ions, more sophisticated mass spectrometers have been installed at FEL facilities, most notably tandem mass spectrometers ${ }^{57,58}$ and Fourier transform ion cyclotron resonance (FT-ICR) mass spectrometers. ${ }^{59-62}$ Ion trapping in combined magnetic and electric fields coupled with FT-ICR mass analysis leads to unparalleled mass resolving power and mass accuracy, and a multitude of ion formation, manipulation and isolation techniques have been developed. ${ }^{63-65} \mathrm{~A}$ wide range of ions whose IR spectra are of interest can be formed by direct ionization or by ion-molecule reactions in the FT-ICR mass spectrometer, and then cleanly isolated so that there is only one species giving rise to the observed photodissociation spectrum.

We describe here the coupling of a FT-ICR mass spectrometer built at University of Florida to the infrared beamline of FELIX in the Netherlands, in order to expand the range of ionic systems for which spectra can be obtained. The instrumentation and experimental protocols, as well as initial studies of two ionic systems, are reported.

\section{EXPERIMENTAL APPARATUS}

Ion trapping and mass analysis are carried out with a laboratory-constructed FT-ICR mass spectrometer (Fig. 1), featuring a $4.7 \mathrm{~T}$ actively shielded superconducting magnet (Cryomagnetics, Inc., Oak Ridge, TN) with a $128 \mathrm{~mm}$ i.d. horizontal bore. Ion formation, irradiation, and detection, as well as pulse sequencing, are controlled by a modular ICR 


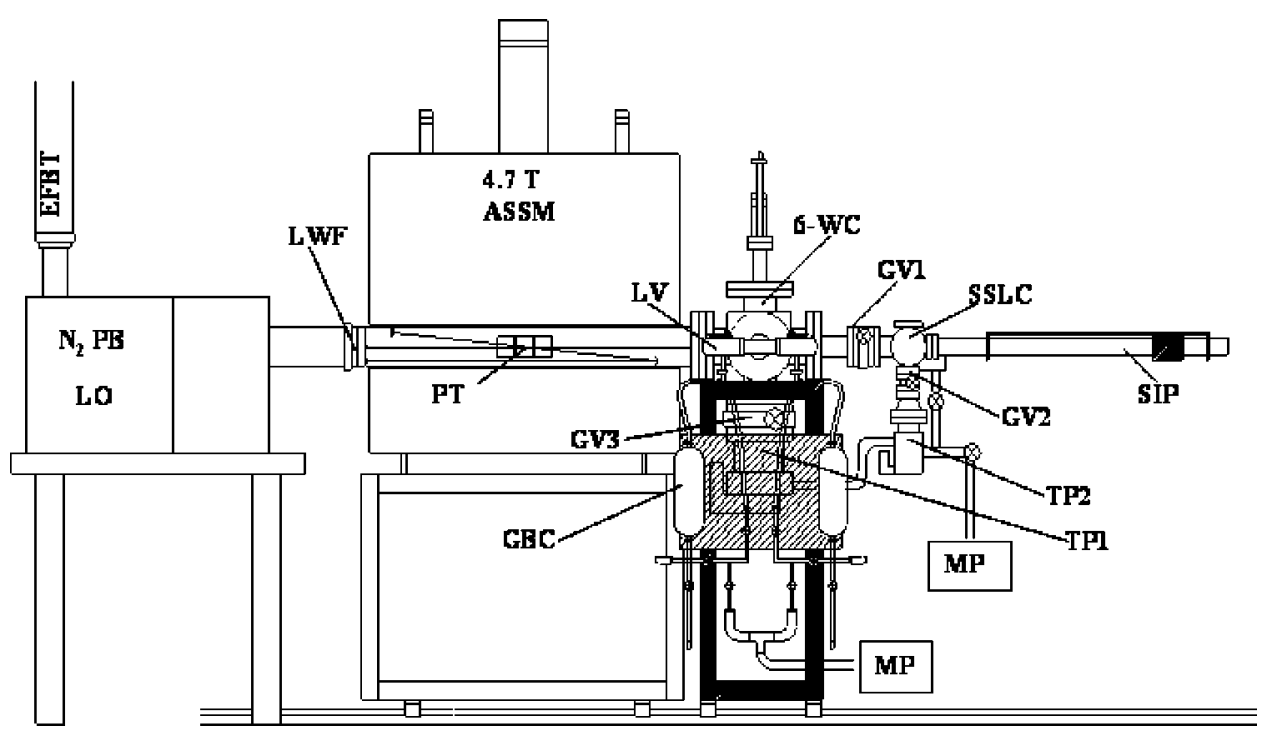

FIG. 1. Schematic representation of the FEL-FT-ICR-MS instrumentation used to obtain IRMPD spectra of gaseous ions. ASSM-actively shielded superconducting magnet; SIP-solids insertion probe; 6-WC-six-way cross; GV1, GV2, GV3-gate valves; SSLCsolids sample loading chamber; TP1, TP2-turbopumps; LV-leak valve; GBC-gas ballast chamber; EFBTevacuated FELIX beam tube; $\mathrm{N}_{2} \mathrm{~PB}$-nitrogen purge box; LO-laser optics; MP-mechanical pumps; LWFlaser window flange; PT-Penning trap.

data acquisition system (MIDAS) ${ }^{66}$ developed at the National High Magnetic Field Laboratory (NHMFL). As initially configured, the instrument was provided with an electron ionization (EI) source positioned inside the magnetic field in the vicinity of the FT-ICR analyzer cell, and a solids insertion probe to facilitate internal laser desorption and matrix assisted laser desorption ionization (MALDI) experiments.

The vacuum system includes a six-way cross (with 8 in. o.d. vacuum flanges) and three manual gate valves (Kurt J. Lesker Co., Clairton, PA). Two of these gate valves (GV1 and GV2 in Fig. 1, with 4.5 and 2.75 in. o.d. vacuum flanges) are attached to the solid sample loading chamber (SSLC in Fig. 1) to permit venting and subsequent pump down during sample loading while maintaining a high vacuum in the main region. The third gate valve (GV3) permits isolation of the main turbomolecular pump from the vacuum chamber. High vacuum is achieved by use of a turbopump (500 L/s, Pfeiffer Vacuum Co., Nashua, NH) and a second turbopump $(70 \mathrm{~L} / \mathrm{s})$, which provides backing of the first pump and roughing of the solid sample loading chamber. The background pressure achieved by these pumps after all modifications made to the vacuum system (feedthroughs and windows) is in the low $10^{-10}$ Torr range after several days of baking at $\sim 120{ }^{\circ} \mathrm{C}$. To provide maximum flexibility for laser alignment and vacuum system maintenance, both the vacuum system and the magnet are mounted on two customized aluminum frame carts (A-Line, Inc., Charlotte, NC) which slide on ball bearing-shaft rail assemblies (Thomson Inc., Port Washington, NY).

Gas phase species, either from gaseous samples or sufficiently volatile liquid or solid samples, are introduced via either of two precision leak valves (Varian Inc., Lexington, MA - LV in Fig. 1), which are provided with pulsed valves and gas ballast chambers to ensure a stable background pressure during sample introduction. Solid samples of low vapor pressure are introduced on the solids insertion probe (SIP in Fig. 1). The pressure is monitored by Convectorr gauges (Varian Inc.) on the inlet system and two inverted magnetron gauges (Varian Inc.) in the main vacuum region and the sample loading chamber.
The FEL used for these experiments (FELIX) has been the core of a user facility since its first operation in the early 1990s. A detailed description has been published elsewhere. ${ }^{46}$ Briefly, the wavelength is continuously tunable between 5 and $250 \mu \mathrm{m},\left(2000-40 \mathrm{~cm}^{-1}\right)$ and the bandwidth can be varied between $0.4 \%$ and $7 \%$ of the central wavelength. To cover this wavelength range, FELIX utilizes two lasers, FEL-1 and FEL-2, working at different electron beam energies. The electrons are produced by an electron gun (injector) and are accelerated by two radiofrequency linear accelerators (r.f. Linacs) to energies of $15-25 \mathrm{MeV}$ and $25-45 \mathrm{MeV}$ to cover the ranges of 25-250 $\mu \mathrm{m}$ (FEL-1) and 5-30 $\mu \mathrm{m}$ (FEL-2), respectively. The wavelength range of FEL-2 can be extended to $2.7 \mu \mathrm{m}$ by using mirrors with a dielectric coating to allow lasing on the third harmonic. The output of FELIX consists of 5-10 $\mu$ s duration macropulses with a total energy of up to $100 \mathrm{~mJ}$, at a repetition rate up to $10 \mathrm{~Hz}$. Each macropulse consists of a train of micropulses of adjustable length $(0.3-5 \mathrm{ps})$ separated by $1 \mathrm{~ns}$. The linewidth of the laser is Fourier-limited according to the micropulse duration. The average power in the macropulses is of the order of $10 \mathrm{~kW}$ and peak power in the micropulses is in the MW range.

This laser is housed in a secure underground vault in the basement of the FOM Institute building. The main laser beam is distributed into different user stations by means of an array of windows and mirrors in a vacuum evacuated tube (EFBT in Fig. 1). To interface the FELIX laser light exiting this tube with the FT-ICR mass spectrometer a nitrogen purge box containing the necessary beam steering and focusing optics was constructed $\left(\mathrm{N}_{2} \mathrm{~PB}\right.$ and LO in Fig. 1). This purge box and optics facilitate the alignment of both FELIX and a second laser used for laser desorption or multiphoton ionization (MPI) experiments, while keeping a dry atmosphere, thus preventing possible absorption of infrared radiation by water vapor in air.

The FELIX laser beam $(5-10 \mathrm{~mm}$ beam diameter) is introduced into the vacuum chamber of the mass spectrometer via a $\mathrm{ZnSe}$ window sealed to the laser window flange (Fig. 2). This laser beam is aligned to pass underneath the 


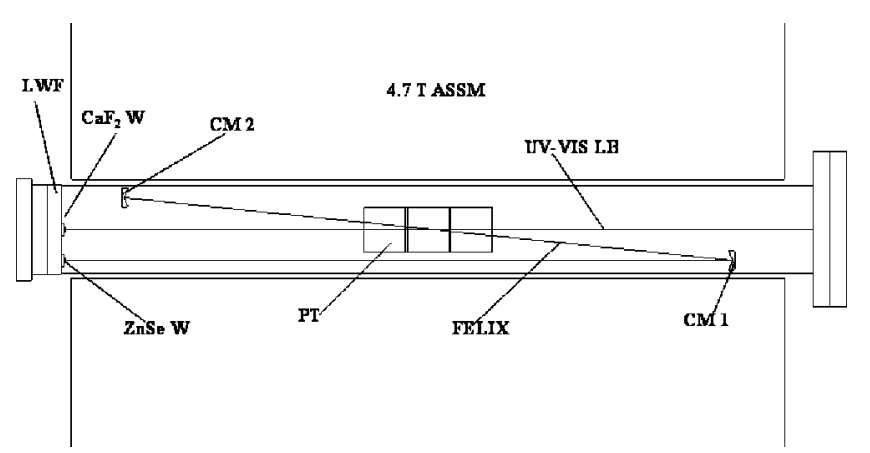

FIG. 2. Expanded view of the laser optics system and the Penning trap in the vacuum chamber. FELIX beam; $\mathrm{ZnSe} \mathrm{W}-\mathrm{ZnSe}$ window for introduction of FELIX beam; LWF-laser window flange; CM1, CM2-copper mirrors; PT-Penning trap; $\mathrm{CaF}_{2} \mathrm{~W}-\mathrm{CaF}_{2}$ window for introduction of $\mathrm{UV}$ and visible lasers; UV-VIS LB-UV or visible laser beam; ASSM-actively shielded superconducting magnet.

ICR cell and is then redirected with a $1 \mathrm{~m}$ radius of curvature polished copper mirror (CM 1 in Fig. 2) to produce fragmentation of ions trapped in the center of the cell (Penning trap). A second polished copper mirror (CM 2 in Fig. 2) with a $0.5 \mathrm{~m}$ radius of curvature reflects the laser back through the ICR cell, thereby doubling the fluence and ensuring that a larger fraction of ions is subjected to laser irradiation. An additional window $\left(\mathrm{CaF}_{2}\right)$ located in the center of the laser introduction flange allows a second laser (UV-VIS LB) to pass along the symmetry axis of the open cylindrical cell for laser desorption or multiphoton ionization (MPI) experiments.

\section{EXPERIMENTAL DESIGN AND RESULTS}

The operation of this FEL-FTICR instrumental set-up has been demonstrated by obtaining the IRMPD spectra of proton-bound dimers, organometallic compounds, and the fluorene molecular ion. Several of these studies have been published elsewhere; ${ }^{61,62}$ here we present application of the apparatus to record IRMPD infrared spectra for the singly-charged chromium-bound dimer of diethyl ether $\left(\mathrm{Cr}\left(\mathrm{C}_{4} \mathrm{H}_{10} \mathrm{O}\right)_{2}^{+}\right)$and for the fluorene molecular ion $\left(\mathrm{C}_{13} \mathrm{H}_{10}^{+}\right)$.

All experiments are controlled using a version of the Modular ICR Data Acquisition Sytem (MIDAS) software ${ }^{66,67}$ which can be externally triggered. The MIDAS system is triggered by a pulse synchronized with the FELIX macropulse train; a shutter blocks FELIX pulses until the desired irradiation period in the FT-ICR experimental event sequence. Typical duty cycles range from 3 to $5 \mathrm{~s}$ depending on ion-molecule reaction times and the number of FELIX macropulses used for irradiation. Four transient response signals (100 K data points) per wavelength are typically acquired and signal averaged while FELIX is scanned by increments of $2-4 \mathrm{~cm}^{-1}$ in the $500-1800 \mathrm{~cm}^{-1}$ range. All experimental transients are digitized and averaged with a digital oscilloscope (Yokogawa DL4200, Tokyo, Japan) prior to storage in a computer by use of LabVIEW software (National Instruments, Austin, TX). After the experiment, the averaged time-domain transients for each wavelength are Fourier transformed. Typically, each $100 \mathrm{~K}$ transient from

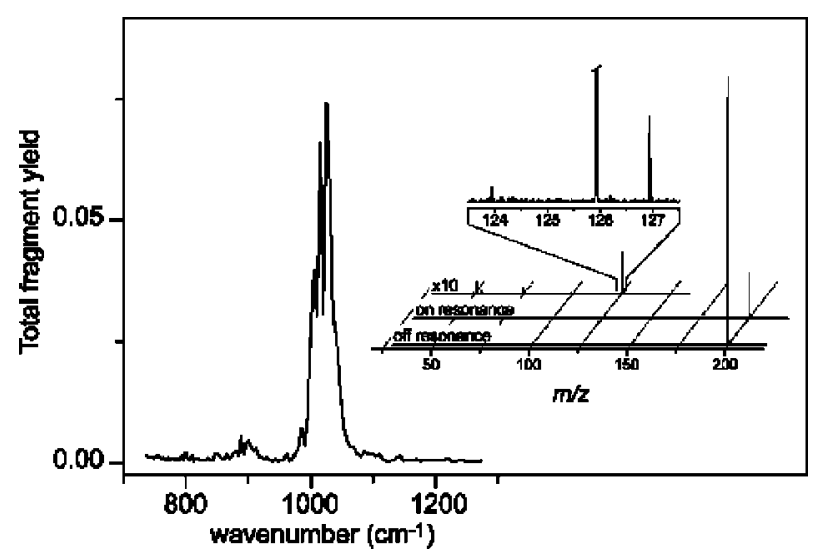

FIG. 3. IRMPD spectrum of $\mathrm{Cr}^{+}\left(\mathrm{C}_{4} \mathrm{H}_{10} \mathrm{O}\right)_{2}$. The inset shows mass spectra taken with the FEL off and on the resonance near $1010 \mathrm{~cm}^{-1}$. Observed dissociation channels at $\mathrm{m} / \mathrm{z}=126$ and $\mathrm{m} / \mathrm{z}=52$ correspond to detachment of one and two ether ligands, respectively. Zooming in on the $\mathrm{m} / z=126$ channel reveals the pattern due to the naturally occurring $\mathrm{Cr}$ isotopes, showing the level of detail typically obtainable with FT-ICR mass spectrometry.

the oscilloscope is zero-filled to $131072\left(=2^{17}\right)$ points, apodized using a Hanning window function and then subjected to FFT and magnitude calculation.

For chromium ion experiments, a 1 in. diam chromium sputter target (Goodfellow, 99.98\%) was mounted on the solids insertion probe and slid into the vacuum can to a position $\sim 50 \mathrm{~cm}$ away from the FT-ICR cell. The fundamental output (1064 nm, $\sim 6 \mathrm{~ns}$ laser pulse width) of a Nd:YAG laser (Eksma NL301G, Vilnius, Lithuania), with the pulse energy set to about $10 \mathrm{~mJ}$, was used as an ablation source. The laser beam was mildly focused (using a lens of $f$ $=1000 \mathrm{~mm}$ ) and coupled into the vacuum can through the center window $\left(\mathrm{CaF}_{2}\right)$ on the laser introduction flange (UVVIS LB shown in Fig. 2). The trap electrode closest to the metal target was kept at $0 \mathrm{~V}$ during the ablation laser pulse and was then switched to its static value typically $3 \mathrm{~ms}$ later, thereby "catching" the $\mathrm{Cr}^{+}$ions. A delay of $3 \mathrm{~s}$ was allowed for chromium ion-molecule reactions with the ether vapor in the cell (at $3 \times 10^{-8}-1 \times 10^{-7}$ Torr), forming predominantly the $\mathrm{Cr}^{+}(\text {ether })_{2}$ complex $\left(\mathrm{Cr}^{+}+\mathrm{C}_{4} \mathrm{H}_{10} \mathrm{O} \rightarrow \mathrm{Cr}\left(\mathrm{C}_{4} \mathrm{H}_{10} \mathrm{O}\right)^{+}\right.$, $\left.\mathrm{Cr}\left(\mathrm{C}_{4} \mathrm{H}_{10} \mathrm{O}\right)^{+}+\mathrm{C}_{4} \mathrm{H}_{10} \mathrm{O} \rightarrow \mathrm{Cr}\left(\mathrm{C}_{4} \mathrm{H}_{10} \mathrm{O}\right)_{2}^{+}\right)$. This species at $\mathrm{m} / z=200$ was subsequently isolated by a stored waveform inverse Fourier Transform (SWIFT) waveform ${ }^{68,69}$ to eject unwanted ions, most notably the $\mathrm{Cr}^{+}$and $\mathrm{Cr}^{+}$(ether) ions, which serve as the signal channels in the IRMPD experiment.

Figure 3 shows the IRMPD spectrum of $\mathrm{Cr}^{+}\left(\mathrm{C}_{4} \mathrm{H}_{10} \mathrm{O}\right)_{2}$ in the $750-1250 \mathrm{~cm}^{-1}$ range, where ethers are known to possess strong absorption bands. Evidence for the processes $\quad \mathrm{Cr}\left(\mathrm{C}_{4} \mathrm{H}_{10} \mathrm{O}\right)_{2}^{+}+n h \nu \rightarrow \mathrm{Cr}\left(\mathrm{C}_{4} \mathrm{H}_{10} \mathrm{O}\right)^{+}+\mathrm{C}_{4} \mathrm{H}_{10} \mathrm{O}$ and $\rightarrow \mathrm{Cr}^{+}+\mathrm{C}_{4} \mathrm{H}_{10} \mathrm{O}$ is seen. The inset shows mass spectra of the isolated parent species at $\mathrm{m} / z=200$ with FELIX off resonance, and with FELIX on the strong resonance near $1010 \mathrm{~cm}^{-1}$. Mass scale expansion clearly reveals the fragments resulting from the loss of a single and both ether ligands and even peaks due to the minor $\mathrm{Cr}$ isotopes. The IR action spectrum is obtained by dividing the total fragment yield (in mass channels 126 and 52) by the total ion signal as the wavelength of FELIX is scanned. 


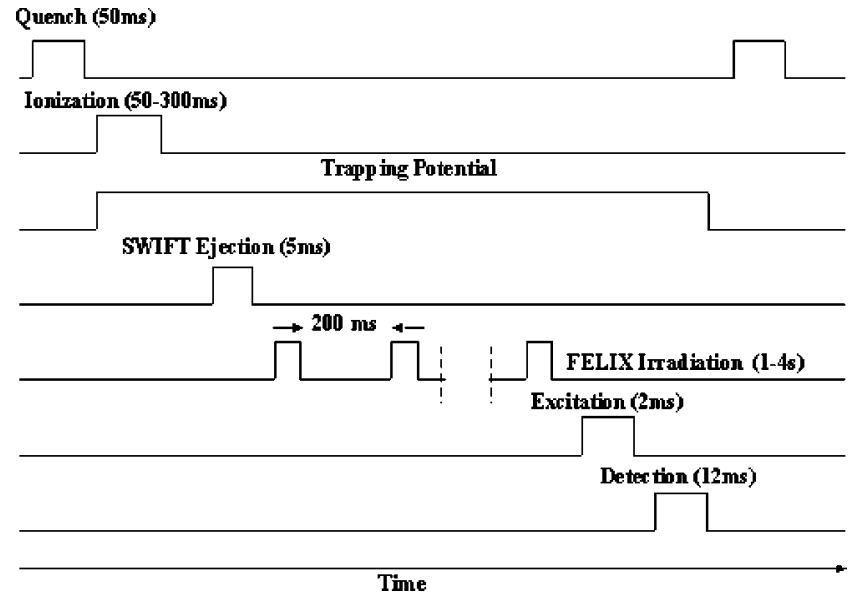

FIG. 4. FT-ICR experimental event sequence used to obtain IRMPD spectra of the fluorene cation.

The IRMPD spectrum of the fluorene molecular ion $\left(\mathrm{C}_{13} \mathrm{H}_{10}^{+}\right)$was obtained by loading a solid fluorene sample into the solids insertion probe and introducing it into the high vacuum region for analysis. The vapor pressure of the sample at room temperature was sufficient to maintain a pressure in the vacuum chamber of $9.0 \times 10^{-8}$ Torr. Positive ions were generated by electron ionization with a $70 \mathrm{eV}$ electron beam of 50-300 ms duration, producing minimal fragmentation and an adequate signal for analysis. After an ionization event, the ions were trapped radially by the magnetic field imposed by the superconducting magnet and axially by applying positive potentials in the range of $1.25-3.0 \mathrm{~V}$ to both trapping electrodes. The parent ion $\left(\mathrm{C}_{13} \mathrm{H}_{10}^{+}, \mathrm{m} / z=166\right)$ was isolated by a SWIFT waveform, to eject unwanted fragment ions formed during the ionization event. Trapped ions were next irradiated with 5-20 FELIX macropulses, separated by $200 \mathrm{~ms}$, over a time period of $1-4 \mathrm{~s}$. The average macropulse energy was $70 \mathrm{~mJ}$. Following the irradiation period, an excitation pulse $\left(\sim 10 \mathrm{~V}_{p-p}\right.$, $\sim 1 \mathrm{GHz} / \mathrm{s}$ sweep rate) typically covering the frequency range from $200 \mathrm{kHz}$ to $4.4 \mathrm{MHz}$ excited both parent and fragment ions to larger cyclotron radii, and after a delay of $2 \mathrm{~ms}$ the ions were detected by digitizing and processing $100 \mathrm{~K}$ time-domain data points (as discussed above for chromium experiments). The pulse sequence employed for these experiments is depicted in Fig. 4.

Figure 5 shows a photodissociation mass spectrum (obtained by following the process $\mathrm{C}_{13} \mathrm{H}_{10}^{+}+n h \nu \rightarrow \mathrm{C}_{13} \mathrm{H}_{9}^{+}+\mathrm{H}$ ) of the fluorene cation. When FELIX is tuned to $1550 \mathrm{~cm}^{-1}$, resonance with an allowed infrared mode occurs and photodissociation (loss of one $\mathrm{H}$ atom) is observed. The offresonance mass spectrum, at $1500 \mathrm{~cm}^{-1}$, is essentially the same as that obtained without FELIX radiation. For fluorene, as well as numerous other PAHs, the main fragmentation channel is loss of one or two hydrogen atoms,${ }^{70}$ which (see Fig. 5) is observed with baseline resolution with the present mass spectrometer. The IRMPD spectrum of the fluorene cation in a QIT has been obtained at FELIX in the past. ${ }^{55}$ However, the mass resolution in those experiments was limited to $m / \Delta m=50$, thus providing insufficient baseline resolution to distinguish two peaks $1 \mathrm{Da}$ apart in the $\mathrm{m} / z, 100-200$ range.

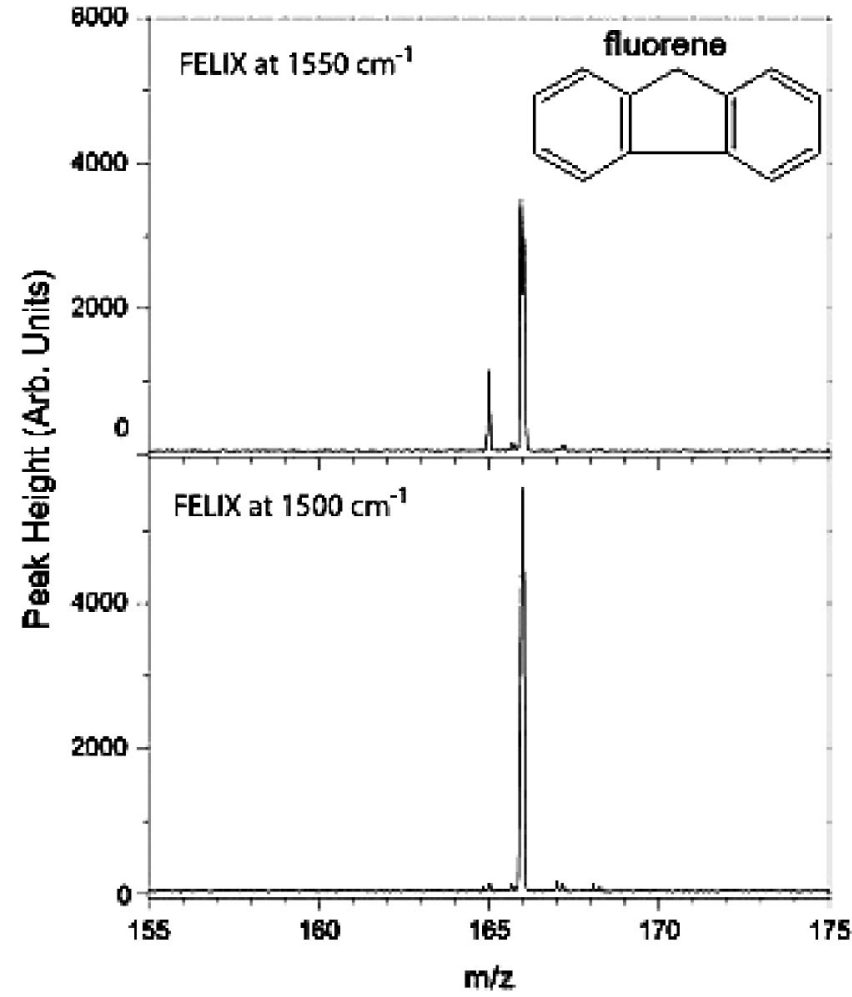

FIG. 5. FT-ICR mass spectra of fluorene $\left(\mathrm{C}_{13} \mathrm{H}_{10}^{+}, m / z=166\right)$ when FELIX was tuned on resonance (top) and off resonance (bottom) with an allowed infrared mode.

The capabilities of the apparatus used in those experiments also did not permit ejection of background fragments (loss of $2 \mathrm{H}$ and $3 \mathrm{H}$ ) without affecting the signal of the parent ion $\left(\mathrm{C}_{13} \mathrm{H}_{10}^{+}\right)$. Those limitations reduced the signal-to-noise ratio for species, such as fluorene, that exhibit $\mathrm{H}$-loss as the main fragmentation pathway. ${ }^{71}$ The present FT-ICR mass spectrometer has a mass resolving power, $\mathrm{m} / \Delta m_{50 \%}$, up to 50000 , in which $\Delta m_{50 \%}$ is peak full width at half-maximum peak height, clearly sufficient to resolve fragment peaks of 1 Da difference.

The IRMPD spectrum is generated by obtaining a series of mass spectra collected as a function of laser wavelength and then plotting fragmentation yield versus wavelength. Figure 6 shows IRMPD spectra of the fluorene cation obtained with FELIX coupled to either a QIT or the FT-ICR mass spectrometer described in this report. Comparison of spectra obtained with the two different mass spectrometers yields general agreement in peak positions but with definite differences. Both spectra reveal a strong band in the vicinity of $1500 \mathrm{~cm}^{-1}$, typical of cationic PAH species, due to coupling of $\mathrm{C}-\mathrm{C}$ stretching modes, and several other weaker absorption lines at lower energies $\left(746,977\right.$, and $\left.1149 \mathrm{~cm}^{-1}\right)$. See Ref. 55 for a more detailed explanation of the spectrum.

One obvious difference between these two spectra is the presence of the broad peak(s) near $1060 \mathrm{~cm}^{-1}$ in the QIT spectrum, which is clearly missing in the FT-ICR spectrum. As mentioned above, as a result of the poor mass resolution of the QIT it was difficult to obtain the spectrum of the isolated fluorene ion. Therefore the spectrum shown in Fig. 6(a) was reported as an assumed observation of a combina- 


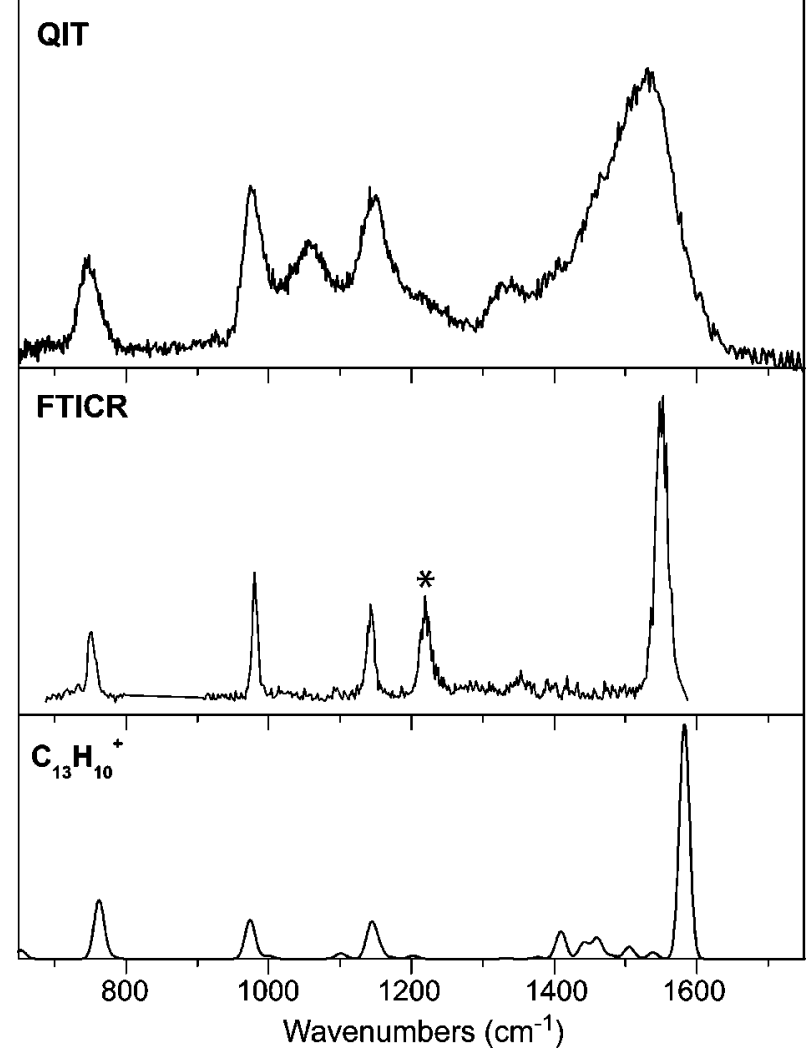

FIG. 6. IRMPD spectrum of fluorene cation $\left(\mathrm{C}_{13} \mathrm{H}_{10}^{+}\right)$obtained by scanning FELIX in the $700-1600 \mathrm{~cm}^{-1}(14.2-6.25$ microns) wavelength region. (Top) Spectrum recorded monitoring the $\mathrm{C}_{2} \mathrm{H}_{n}$ loss channel in a QIT from Ref. 55; (Center) Spectrum recorded monitoring the H-loss channel in the FT-ICR mass spectrometer described in this paper. The vertical axes represents fragmentation yield. (Bottom) Theoretically calculated (Becke's Three Parameter Hybrid Functional using the Lee, Yang, and Parr Correlation Functional with Dunning/Huzinaga full double zeta basis sets including diffuse and polarization functions-B3LYP/D95 $(d, p)$ ) spectrum convoluted with a $30 \mathrm{~cm}^{-1}$ Lorentzian line profile.

tion (4/1) of the infrared spectrum of fluorene cation $\left(\mathrm{C}_{13} \mathrm{H}_{10}^{+}\right)$and that of the dehydrogenated fluorene ion $\left(\mathrm{C}_{13} \mathrm{H}_{9}^{+}\right)$(see Ref. 55). As illustrated in Fig. 5 the mass spectra obtained with the FT-ICR mass spectrometer achieve isolation of the parent peak with baseline resolution for the fragment ion, thereby limiting the observation of photodissociation to the fluorene cation $\left(\mathrm{C}_{13} \mathrm{H}_{10}^{+}\right)$only. Therefore, the absence of the $1060 \mathrm{~cm}^{-1}$ peak in the FT-ICR spectrum supports the conclusion that the spectrum obtained with the QIT was a combination of those for both the $\mathrm{C}_{13} \mathrm{H}_{10}^{+}$and the $\mathrm{C}_{13} \mathrm{H}_{9}^{+}$ion. Another evident difference is the presence of the new band at $1220 \mathrm{~cm}^{-1}$ in the FT-ICR spectrum, marked with a $*$, which also seems to be present at low intensity in the QIT spectrum, but does not match any peak in the corresponding calculation. Investigations of its exact origin are ongoing and will be reported in a future publication.

One striking feature of the FT-ICR-derived infrared spectrum is that the peaks are significantly narrower than those in the spectrum obtained using the QIT. Since the $\mathrm{H}$-loss channel cannot be observed directly in the QIT experiment, the FELIX beam must be focused more tightly ( $f$ $=7.5 \mathrm{~cm}$ ) in order to access higher energy fragmentation channels involving carbon loss. As mentioned in the Intro- duction, the resulting higher internal energies of the ions cause the spectral lines to broaden. In contrast, lower internal energies are required to observe dissociation when using the FT-ICR mass spectrometer, since the lowest energy $(2.7 \mathrm{eV}$ binding energy $)^{71} \mathrm{H}$-loss channel can be resolved. One other factor potentially contributing to the narrower lines in the FT-ICR experiment is considerably longer trapping between ion formation and FELIX irradiation, allowing more complete radiative cooling of the ions.

The FT-ICR/FEL facility at FELIX will extend the field of infrared spectroscopy to ions of many interesting molecular systems. Implementation of a guide for externally produced ions is currently underway, which will allow study of biologically relevant species produced from MALDI and electrospray ionization (ESI) sources, which are also currently under construction. The ability to differentiate isomeric ions based on their vibrational spectra will greatly expand the capabilities of mass spectrometry, both as a research tool and for solving more routine analytical problems. The Fourier transform ion cyclotron resonance-free electron laser facility described here is available for use by any scientist whose experiments would benefit from obtaining IR spectra of ions of particular interest in their ongoing research. ${ }^{72}$

\section{ACKNOWLEDGMENTS}

The authors gratefully acknowledge the University of Florida Chemistry Department Machine Shop (Joe Shalosky and Todd Prox) for their help in the design and construction of some components of the FTICR mass spectrometer, and Dr. Kathryn Williams for helpful comments on the manuscript. Construction and shipping of the instrument was made possible with funding from the National High Field FT-ICR Facility (National Science Foundation Grant No. CHE9909502) at the National High Magnetic Field Laboratory, Tallahassee, Florida. This work is part of the research program of FOM, which is financially supported by the Nederlandse Organisatie voor Wetenschappelijk Onderzoek. The authors thank Professor Robert Dunbar for permission to use the $\mathrm{Cr}^{+}$-diethyl ether data. The authors also thank the FELIX and FOM staff, particularly Jan Pluijgers, for technical assistance.

${ }^{1}$ L. J. Allamandola, A. Tielens, and J. R. Barker, Astrophys. J., Suppl. Ser. 71, 733 (1989).

${ }^{2}$ J. A. Gerlt, M. M. Kreevoy, W. W. Cleland, and P. A. Frey, Chem. Biol. 4, 259 (1997).

${ }^{3}$ G. A. Olah, My Search for Carbocations and Their Role in Chemistry, in "Nobel Lectures Chemistry, 1991-1995" (World Scientific, Singapore, 1996).

${ }^{4}$ J. A. Leary and P. B. Armentrout, Int. J. Mass. Spectrom. 204, ix (2001).

${ }^{5}$ H. A. Schwarz, J. Chem. Phys. 67, 5525 (1977).

${ }^{6}$ T. Oka, Phys. Rev. Lett. 45, 531 (1980).

${ }^{7}$ C. S. Gudeman, M. H. Begemann, J. Pfaff, and R. J. Saykally, Phys. Rev. Lett. 50, 727 (1983).

${ }^{8}$ E. R. Keim, M. L. Polak, J. C. Owrutsky, J. V. Coe, and R. J. Saykally, J. Chem. Phys. 93, 3111 (1990).

${ }^{9}$ H. S. Kim and R. J. Saykally, Rev. Sci. Instrum. 74, 2488 (2003).

${ }^{10}$ G. Hilpert, H. Linnartz, M. Havenith, J. J. Termeulen, and W. L. Meerts, Chem. Phys. Lett. 219, 384 (1994)

${ }^{11}$ T. Speck, H. Linnartz, and J. P. Maier, J. Chem. Phys. 107, 8706 (1997).

${ }^{12}$ H. Linnartz, D. Verdes, and T. Speck, Rev. Sci. Instrum. 71, 1811 (2000).

${ }^{13}$ J. Szczepanski and M. Vala, J. Phys. Chem. 95, 2792 (1991).

${ }^{14}$ M. F. Zhou, L. Andrews, and C. W. Bauschlicher, Chem. Rev. (Washing- 
ton, D.C.) 101, 1931 (2001).

${ }^{15}$ D. M. Hudgins, S. A. Sandford, and L. J. Allamandola, J. Phys. Chem. 98, 4243 (1994).

${ }^{16}$ P. Freivogel, J. Fulara, D. Lessen, D. Forney, and J. P. Maier, Chem. Phys. 189, 335 (1994).

${ }^{17}$ A. M. Smith-Gicklhorn, M. Lorenz, R. Kolos, and V. E. Bondybey, J. Chem. Phys. 115, 7534 (2001).

${ }^{18}$ C. Jobling, L. d'Hendercourt, A. Léger, and D. Deforneau, Astron. Astrophys. 281, 923 (1994).

${ }^{19}$ M. A. Duncan, Int. J. Mass. Spectrom. 200, 545 (2000).

${ }^{20}$ M. Okumura, L. I. Yeh, and Y. T. Lee, J. Chem. Phys. 83, 3705 (1985).

${ }^{21}$ M. Okumura, L. I. Yeh, J. D. Myers, and Y. T. Lee, J. Chem. Phys. 85, 2328 (1986)

${ }^{22}$ L. I. Yeh, M. Okumura, J. D. Myers, J. M. Price, and Y. T. Lee, J. Chem. Phys. 91, 7319 (1989).

${ }^{23}$ S. A. Nizkorodov, O. Dopfer, T. Ruchti, M. Meuwly, J. P. Maier, and E. J. Bieske, J. Phys. Chem. 99, 17118 (1995).

${ }^{24}$ H. Piest, G. von Helden, and G. Meijer, J. Chem. Phys. 110, 2010 (1999).

${ }^{25}$ J. M. Bakker, R. G. Satink, G. von Helden, and G. Meijer, Phys. Chem. Chem. Phys. 4, 24 (2002).

${ }^{26}$ N. Solca and O. Dopfer, Angew. Chem., Int. Ed. 41, 3628 (2002).

${ }^{27}$ T. Sawamura, A. Fujii, S. Sato, T. Ebata, and N. Mikami, J. Phys. Chem. 100, 8131 (1996).

${ }^{28}$ D. van Heijnsbergen, G. von Helden, G. Meijer, P. Maitre, and M. A. Duncan, J. Am. Chem. Soc. 124, 1562 (2002).

${ }^{29}$ N. Solca and O. Dopfer, J. Am. Chem. Soc. 125, 1421 (2003).

${ }^{30}$ Y. Honkawa, Y. Inokuchi, K. Ohashi, N. Nishi, and H. Sekiya, Chem. Phys. Lett. 376, 244 (2003).

${ }^{31}$ J.-C. Jiang, Y.-S. Wang, H.-C. Chang, S. H. Lin, Y. T. Lee, G. NiednerSchatteburg, and H.-C. Chang, J. Am. Chem. Soc. 122, 1398 (2000).

${ }^{32}$ J. G. Black, E. Yablonovitch, N. Bloembergen, and S. Mukamel, Phys. Rev. Lett. 38, 1131 (1977).

${ }^{33}$ E. R. Grant, P. A. Schulz, A. S. Sudbo, Y. R. Shen, and Y. T. Lee, Phys. Rev. Lett. 40, 115 (1978).

${ }^{34}$ V. N. Bagratashvili, V. S. Letokhov, A. A. Makarov, and E. A. Ryabov, Multiple Photon Infrared Laser Photophysics and Photochemistry (Gordon and Breach, New York, 1985).

${ }^{35}$ K. K. Lehmann, G. Scoles, and B. H. Pate, Annu. Rev. Phys. Chem. 45, 241 (1994).

${ }^{36}$ J. Oomens, A. G. G. M. Tielens, B. G. Sartakov, G. von Helden, and G. Meijer, Astrophys. J. 591, 968 (2003).

${ }^{37}$ M. Kamioka, S. Arai, Y. Ishikawa, S. Isomura, and N. Takamiya, Chem. Phys. Lett. 119, 357 (1985).

${ }^{38}$ G. N. Makarov and A. N. Petin, Chem. Phys. 266, 125 (2001).

${ }^{39}$ C. H. Watson, J. A. Zimmerman, J. E. Bruce, and J. R. Eyler, J. Phys. Chem. 95, 6081 (1991).

${ }^{40}$ R. D. F. Settle and T. R. Rizzo, J. Chem. Phys. 97, 2823 (1992).

${ }^{41}$ M. Polianski, O. V. Boyarkin, T. R. Rizzo, V. M. Apatin, V. B. Laptev, and E. A. Ryabov, J. Phys. Chem. A 107, 8578 (2003).

${ }^{42}$ J. L. Lyman, B. E. Newnam, J. W. Early, and A. F. G. van der Meer, J. Phys. Chem. A 101, 49 (1997).

${ }^{43}$ P. G. O'Shea and H. P. Freund, Science 292, 1853 (2001).

${ }^{44}$ W. B. Colson, E. D. Johnson, M. J. Kelley, and H. A. Schwettman, Phys. Today 55, 35 (2002).
${ }^{45} \mathrm{http}: / /$ www.elettra.trieste.it/projects/roundtable/facilities.html

${ }^{46}$ D. Oepts, A. F. G. Vandermeer, and P. W. Vanamersfoort, Infrared Phys. Technol. 36, 297 (1995).

${ }^{47}$ R. C. Dunbar, Int. J. Mass. Spectrom. 200, 571 (2000).

${ }^{48}$ C. A. Wight and J. L. Beauchamp, J. Am. Chem. Soc. 103, 6499 (1981).

${ }^{49}$ L. Thorne and J. Beauchamp, Gas Phase Ion Chemistry (Academic, Orlando, 1984), Vol. 3.

${ }^{50}$ S. K. Shin and J. L. Beauchamp, J. Am. Chem. Soc. 112, 2057 (1990).

${ }^{51}$ D. M. Peiris, M. A. Cheeseman, R. Ramanathan, and J. R. Eyler, J. Phys. Chem. 97, 7839 (1993).

${ }^{52}$ D. M. Peiris, J. M. Riveros, and J. R. Eyler, Int. J. Mass Spectrom. Ion Processes 159, 169 (1996).

${ }^{53}$ J. Oomens, A. J. A. van Roij, G. Meijer, and G. von Helden, Astrophys. J. 542, 404 (2000).

${ }^{54}$ R. E. March, J. Mass Spectrom. 32, 351 (1997).

${ }^{55}$ J. Oomens, G. Meijer, and G. von Helden, J. Phys. Chem. A 105, 8302 (2001).

${ }^{56}$ J. Oomens, B. G. Sartakov, A. Tielens, G. Meijer, and G. von Helden, Astrophys. J. 560, L99 (2001).

${ }^{57}$ K. R. Asmis, M. Bruemmer, C. Kaposta, G. Santambrogio, G. von Helden, G. Meijer, K. Rademann, and L. Woeste, Phys. Chem. Chem. Phys. 4, 1101 (2002)

${ }^{58}$ K. R. Asmis, N. L. Pivonka, G. Santambrogio, M. Brummer, C. Kaposta, D. M. Neumark, and L. Woste, Science 299, 1375 (2003).

${ }^{59}$ J. Lemaire, P. Boissel, M. Heninger, G. Mauclaire, G. Bellec, H. Mestdagh, A. Simon, S. L. Caer, J. M. Ortega, F. Glotin, and P. Maitre, Phys. Rev. Lett. 89, 273002 (2002).

${ }^{60}$ W. Jones, P. Boissel, B. Chiavarino, M. E. Crestoni, S. Fornarini, J. Lemaire, and P. Maitre, Angew. Chem., Int. Ed. 42, 2057 (2003).

${ }^{61}$ J. Oomens, D. T. Moore, G. von Helden, G. Meijer, and R. C. Dunbar, J. Am. Chem. Soc. 126, 724 (2004).

${ }^{62}$ D. T. Moore, J. Oomens, L. Van Der Meer, G. Von Helden, G. Meijer, J. Valle, A. G. Marshall, and J. R. Eyler, ChemPhysChem 5, 740 (2004).

${ }^{63}$ I. J. Amster, J. Mass Spectrom. 31, 1325 (1996).

${ }^{64}$ A. G. Marshall, C. L. Hendrickson, and G. S. Jackson, Mass Spectrom. Rev. 17, 1 (1998).

${ }^{65}$ A. G. Marshall, Int. J. Mass. Spectrom. 200, 331 (2000).

${ }^{66}$ M. W. Senko, J. D. Canterbury, S. H. Guan, and A. G. Marshall, Rapid Commun. Mass Spectrom. 10, 1839 (1996).

${ }^{67}$ G. T. Blakney, G. van der Rest, J. R. Johnson, M. A. Freitas, J. J. Drader, S. D.-H. Shi, C. L. Hendrickson, N. L. Kelleher, and A. G. Marshall, "Further Improvements to the MIDAS Data Station for FT-ICR Mass Spectrometry," 49th Amer. Soc. Mass Spectrom. Conf. on Mass Spectrom. and Allied Topics, Chicago, IL, May, 2001.

${ }^{68}$ A. G. Marshall, T. C. L. Wang, and T. L. Ricca, J. Am. Chem. Soc. 107, 7893 (1985).

${ }^{69}$ S. H. Guan and A. G. Marshall, Int. J. Mass Spectrom. Ion Processes 158, 5 (1996).

${ }^{70}$ S. P. Ekern, A. G. Marshall, J. Szczepanski, and M. Vala, J. Phys. Chem. A 102, 3498 (1998)

${ }^{71}$ J. Szczepanski, M. J. Dibben, W. Pearson, J. R. Eyler, and M. Vala, J. Phys. Chem. A 105, 9388 (2001).

${ }^{72}$ For more information, contact Dr. Oomens or Professor Eyler. 